\title{
Processamento mínimo de palmito juçara embalado em salmoura acidificada
}

\section{Minimal processing of juçara's heart palm packed in brine acidified}

\author{
Paula Porrelli Moreira da Silva ${ }^{1 *}$; Leandro Francisco do Carmo ${ }^{2}$; \\ Guilherme Mei Silva ${ }^{3}$; Paula Fernanda Souza Aoki ${ }^{4}$; Marta Helena Fillet Spoto ${ }^{5}$
}

\section{Resumo}

A palmeira juçara (Euterpe edulis), nativa da Mata Atlântica, é uma das mais exploradas para retirada do palmito; tratando-se de produto importante no bioma, a palmeira foi eliminada em vastas áreas. O objetivo deste trabalho foi analisar a viabilidade da metodologia "minimamente processados" para o palmito de juçara. A matéria-prima foi obtida através de Plano de Manejo Sustentável licenciado pelo IBAMA, Fundação Florestal e DPRN. O processamento iniciou-se com a retirada das bainhas externas e corte do palmito, com posteriores imersão em solução de metabissulfito de sódio $\left(\mathrm{Na}_{2} \mathrm{~S}_{2} \mathrm{O}_{5}\right)$ na concentração 200 ppm, higienização com solução clorada e imersão em salmoura acidificada de espera até o envase. Os toletes foram acondicionados em sacos plásticos de polietileno, contendo solução acidificada nas concentrações A $0,225 \%$, B $0,375 \%$, C $0,6 \%$, D $0,825 \%$ determinadas por curva de titulação. A coloração ficou mais clara nos tratamentos $\mathrm{C}$ e $\mathrm{D}$, devido à solução mais ácida, proporcionando maior inativação das enzimas. O produto mostrou-se seguro para o consumo, porque tanto $\mathrm{pH}$ (abaixo de 4,5) quanto acidez titulável nos quatro casos estavam adequados. Apesar dos resultados positivos, o processamento mínimo de palmito de juçara não é efetivo devido ao escurecimento, inviabilizando sua comercialização. Para interrompê-lo, é necessária a etapa de branqueamento, não o caracterizando como minimamente processado.

Palavras-chave: Euterpe edulis, mata atlântica, acidificação

\begin{abstract}
The juçara's palm (Euterpe edulis), native to the Atlantic Forest is one of the palms most exploited for the removal of heart palm and the tree was removed in large areas. The aim of this study was to examine the feasibility of the methodology of "minimally processed" in juçara's palm. The raw material was obtained by COOPERÁGUA, Sete Barras (SP) through a Sustainable Management Plan culminating in a permit issued by IBAMA, Forestry Foundation and DPRN. The process began with the withdrawal of external sheaths and cut, with subsequent immersion in a solution of sodium metabisulphite $\left(\mathrm{Na}_{2} \mathrm{~S}_{2} \mathrm{O}_{5}-200 \mathrm{ppm}\right)$, sanitize with a chlorine solution and soak in brine acidified to wait until the filling. The cuttings were placed in polyethylene bags containing acidified solution at concentrations A $0.225 \%$, B $0.375 \%, \mathrm{C} 0.6 \%$, $\mathrm{D} 0.825 \%$ determined by titration curve. The staining became clearer in treatments $\mathrm{C}$ and $\mathrm{D}$, due to more acidity, resulting in higher inactivation of enzymes. Even with these positive results, were concluded that minimal processing of juçara is not effective due to the blackout, preventing its commercialization. To stop it requires the bleaching step, which does not characterize it as minimally processed.
\end{abstract}

Key words: Euterpe edulis, mata atlântica, acidification

1 Doutoranda em Energia Nuclear na Agricultura. Centro de Energia Nuclear na Agricultura. Universidade de São Paulo, CENA/ USP. E-mail: pporrelli@uol.com.br

2 Dr. em Agronomia. Escola Superior de Agricultura "Luiz de Queiroz". Universidade de São Paulo, ESALQ/USP. E-mail: drleandrocarmo@gmail.com

3 Mestrando em Ciência e Tecnologia de Alimentos. ESALQ/USP. E-mail: meisilva_bio@yahoo.com.br

4 Nutricionista. União das Instituições de Serviços, Ensino e Pesquisa Ltda, UNISEP. E-mail: paula_aoki@yahoo.com.br

5 Prof ${ }^{\mathrm{a}} \mathrm{Dr}^{\mathrm{a}}$ da Escola Superior de Agricultura. ESALQ/USP. E-mail: mhfspoto@esalq.usp.br

* Autor para correspondência 


\section{Introdução}

O palmito vem sendo utilizado na alimentação dos brasileiros desde tempos remotos, no início pelos indígenas e posteriormente pelos colonizadores portugueses e escravos. $\mathrm{O}$ seu consumo se acentuou durante a expansão do cultivo de café, ocorrida no Sul e Sudeste do país, onde a palmeira juçara (Euterpe edulis) foi utilizada para construção de moradias de colonos utilizando o caule para parede e assoalho, a palha (folha) para cobertura das casas e o palmito como alimento, sua utilização na alimentação se consolidou, por volta de 1932, nessas regiões do Brasil (YUYAMA, 2005). Suas características sensoriais peculiares fizeram com que o consumo fosse sempre crescente até atingir uma grande demanda.

A juçara é nativa do Domínio da Floresta Tropical Atlântica do Brasil. Sua área de ocorrência se estende desde o Sul da Bahia $\left(15^{\circ} \mathrm{S}\right)$ até o Norte do Rio Grande do Sul ( $\left.30^{\circ} \mathrm{S}\right)$ no litoral, adentrando, no Sul até o Leste do Paraguai e Norte da Argentina $\left(57^{\circ} \mathrm{W}\right)$ (CONTE, 2004). O palmito proveniente desta espécie é um dos mais importantes produtos não madeiráveis aproveitados na Floresta Atlântica.

O palmito é constituído por três partes: a) caulinar (basal), de maior diâmetro, situada na região mais baixa do talo do palmito, é comercializada também como conserva em vidro nas formas de rodelas inteiras, metades, triângulos, picadinho e em bolas; b) apical, situada no ápice do talo, apresenta aspecto foliar e diâmetro reduzido, a qual é geralmente incluída como picadinho na conserva; c) creme de palmito, coração ou tolete, localizada na região intermediária do talo entre as partes caulinar e apical, é a porção mais nobre do palmito (palmito de primeira), por esse motivo, tem maior valor comercial (CHAIMSOHN, 2001; RAUPP, 2001).

Os palmitos provenientes de palmeiras como juçara (E. edulis), açaí (Euterpe oleracea) e palmeira real da Austrália (Archontophoenix alexandrae) apresentam altos níveis das enzimas oxidativas, as quais depreciam a qualidade do produto por produzirem escurecimento, tanto no palmito em conserva (quando inadequadamente processado) como, principalmente, no fresco (FERREIRA et al., 1982; SOARES, 1997) e, por isso, tais processamentos exigem o uso de aditivos antioxidantes para inibir tais efeitos.

Hortaliças refrigeradas, como o palmito, são consideradas minimamente processadas quando fisicamente alteradas. No entanto, é necessário que permaneçam no estado fresco. Essa transformação tecnológica, mesmo sendo mínima, produz destruição do tecido, por conseguinte, além de facilitar a contaminação microbiana, ocorre liberação de enzimas e de seus substratos, propiciando a ocorrência de reações enzimáticas que podem alterar as características sensoriais do produto (CLEMENT; BOVI, 1999; MORETTI, 2001; WILEY, 1997).

As reações de oxidações estimuladas pelo oxigênio, enzimáticas ou químicas, as quais diminuem a qualidade do palmito, principalmente sua coloração, pode ser minimizada, aplicando-se práticas eficientes durante o processamento, como submergir a matéria-prima em água acidificada, enquanto não envasada, e a execução de exaustão, que tem a finalidade de expulsar o oxigênio presente no alimento (GAVA, 1978; CAMARGO, 1984; CHEFTEL; CHEFTEL; BESANÇON, 1992; LINDEN; LORIENT, 1996).

A acidificação com ácidos orgânicos, como o ácido cítrico, é recomendada para alimentos minimamente processados poucos ácidos, como o palmito fresco que tem $\mathrm{pH}$ entre 5,6 e 6,2, principalmente quando o produto for embalado com restrição de $\mathrm{O}_{2}$ (TONET; FERREIRA; OTOBONI, 1999). Para se mostrar eficiente, esse tratamento deve ajustar o $\mathrm{pH}$ do alimento para abaixo de 4,5, pois, o $\mathrm{pH} 4,5$ é considerado o mínimo para o crescimento do Clostridium botulinum (CHEFTEL; CHEFTEL; BESANÇON, 1992; FRANCO; LANDGRAF, 1996; RAUPP, 2001; WILEY, 1997).

Produtos como o palmito estão sujeitos ao desenvolvimento de Clostridium botulinum quando 
não é aplicado um procedimento de tratamento térmico eficiente para obter a esterilização comercial e também quando o $\mathrm{pH}$ do alimento permanece superior a 4,5. Esta bactéria é capaz de produzir uma toxina que, quando ingerida pelo homem, causa uma síndrome conhecida como Botulismo. Os esporos de C. botulinum podem ser carregados para o produto envasado a partir do solo e pelo talo de palmito (PASCHOALINO; CAMPOS; LEITÃO, 1989; RAUPP, 2001).

A crescente demanda dos consumidores por alimentos mais naturais ou frescos fez com que novas formas de preservação fossem estudadas, visando minimizar perdas qualitativas de produtos, mantendo-os mais próximos do in natura e com uma vida de prateleira mais estável.

A aplicação de tratamento térmico, com o propósito de gerar segurança, em conserva de palmito a partir de $\mathrm{pH}$ in natura (ZAPATA; QUAST, 1975; TONET; FERREIRA; OTOBONI, 1999; CHAIMSOHN, 2000) danificaria suas propriedades sensoriais, principalmente a textura, com conseqüente perda de qualidade para o consumidor, diminuindo seu valor comercial (PASCHOALINO, 1994, 1997; RAUPP, 2001). O objetivo deste trabalho foi, portanto, analisar a viabilidade da metodologia de "minimamente processados" em palmito de juçara, aliando-se os benefícios de palmito in natura e acidificação eficiente do produto embalado em salmoura, feita de modo que o $\mathrm{pH}$ de equilíbrio permaneça abaixo ou igual a 4,5, permitindo que o alimento possua textura agradável, com uma prática tecnológica segura, pois é capaz de bloquear o desenvolvimento dos esporos do C. botulinum.

\section{Material e Métodos}

\section{Matéria-prima}

A matéria prima foi obtida pela COOPERÁGUA, Bairro do Guapiruvu em Sete Barras (SP), através de um Plano de Manejo Sustentável culminando em uma licença emitida pelo IBAMA, Fundação Florestal e DPRN. O processamento teve início na própria área experimental, através da retirada parcial das bainhas mais externas. Os talos foram colocados em sacos de polietileno e transportados em temperatura ambiente até a Planta Piloto de Processamento de Alimentos, situada no Departamento Agroindústria, Alimentos e Nutrição (ESALQ/USP), Piracicaba (SP), onde foram realizadas as demais etapas de preparo do palmito.

\section{Processamento}

O fluxograma do processamento mínimo do palmito de juçara está apresentado na (Figura 1).

O processamento mínimo do palmito iniciou-se pela remoção das capas externas do palmito com a ajuda de facões de aço inoxidável; seguida pelo corte dos toletes em unidades de $9 \mathrm{~cm}$ de comprimento; tomou-se o cuidado de não incorporar as partes endurecidas. O critério para o aproveitamento dos toletes descascados teve como base a resistência oferecida ao corte, isto é, só foram utilizados os que permitiam a penetração da faca sob leve pressão.

Imediatamente após o corte, os toletes foram limpos e imersos em solução de metabissulfito de sódio $\left(\mathrm{Na}_{2} \mathrm{~S}_{2} \mathrm{O}_{5}-\right.$ agente antioxidante e antimicrobiano) na concentração 200 ppm durante 10 minutos, com o intuito de interromper a ação das enzimas de escurecimento presentes em abundância no palmito de juçara, e também de inibir a proliferação de microrganismos no alimento. Após este período, foi realizada higienização mais completa nos toletes em solução de cloro na concentração 200 mg L-1 durante 10 minutos.

Em seguida, os toletes foram colocados em solução de espera preparada com 5\% de cloreto de sódio $(\mathrm{NaCl})$ e $1 \%$ de ácido cítrico, até o momento da embalagem. Os toletes de palmito juçara foram acondicionados em sacos de polietileno com capacidade para $500 \mathrm{~mL}$ de produto, na proporção 1:1 (300 g palmito e $300 \mathrm{~mL}$ de solução acidificada), já contendo soluções acidificadas em 4 concentrações diferentes de ácido cítrico, a saber: 
- solução A: 0,025\% de ácido cítrico para pH 4,3

- solução B: 0,375\% de ácido cítrico para pH 4,0

- solução C: 0,6\% de ácido cítrico para pH 3,7

- solução D: $0,825 \%$ de ácido cítrico para $\mathrm{pH}$ 3,5

As concentrações de ácido cítrico na solução foram determinadas pela de curva de titulação, realizada após o corte dos toletes, de acordo com a metodologia desenvolvida por Zapata e Quast (1975).

Após o acondicionamento dos toletes na embalagem, foram armazenados sob refrigeração $\left(5^{\circ} \mathrm{C}\right)$ durante 14 dias. As avaliações dos toletes de palmito de juçara minimamente processados foram feitas utilizando-se um saco de polietileno de cada solução para as análises, em 3 períodos: 1, 7, 14 dias após o processamento.
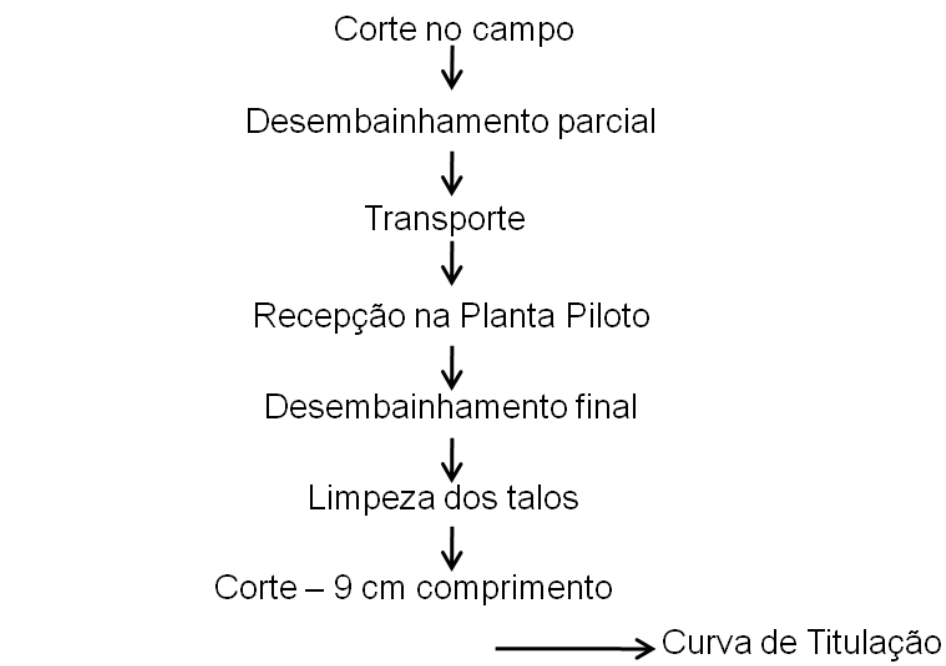

Imersão em solução de metabissulfito (200ppm/10 min)

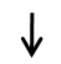

Imersão em solução de SUMAVEG ${ }^{\circledR}(0,66 \% / 10$ min $)$ $\stackrel{\downarrow}{\downarrow}$ Imersão em solução de espera $(5 \% \mathrm{NaCl}+1 \%$ Ác. Cítrico) Envase: sacos polietileno (500 mL) com solução acidificada

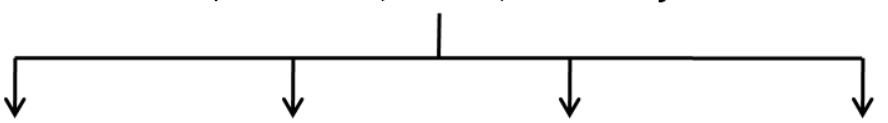
A) $\mathrm{pH} 4,3$
B) $\mathrm{pH} 4,0$
C) $\mathrm{pH} 3,7$
D) $\mathrm{pH} 3,5$
$0,225 \%$ ác.
$0,375 \%$ ác.
$0,6 \%$ ác
$0,825 \%$ ác.
cítrico cítrico
cítrico
cítrico

Armazemamento sob refrigeração $-5^{\circ} \mathrm{C}$

Figura 1. Fluxograma do processamento mínimo do palmito de juçara.

NOTA: SUMAVEG ${ }^{\circledR}$ é nome comercial de produto que possui como princípio ativo o Dicloro S-Triazinatriona Sódica Dihidratada em pó ( $3 \%$ de cloro ativo). 
Avaliações fisicas e químicas

1 Coloração (L, a*, b*)

Avaliada através do colorímetro Color MeterMinolta 200b. Registram-se mudanças na coloração, brilho e saturação das cores através do valor $\mathrm{L}$ (Luminosidade), do valor a* (vermelho ao verde), e do valor $b^{*}$ (amarelo ao azul). A partir desses valores obtém-se o valor Croma, e o ângulo de cor Hue, de acordo com Minolta (1998):

Croma: $C=\sqrt{(a *)^{2}+(b *)^{2}}$

Ângulo Hue: $h=\tan ^{-1}\left(\frac{a^{*}}{b^{*}}\right)$

$2 \mathrm{pH}$

Determinado em potenciômetro da marca TECNAL, modelo TEC3-MP, a partir de amostras liquefeitas, segundo método $\mathrm{n}^{\circ} 981.12$ da AOAC (2005).

\section{Acidez titulável}

Determinada e calculada por titulometria a partir do volume em $\mathrm{mL}$ de $\mathrm{NaOH} 1 \mathrm{M}$ e indicador fenolftaleína, segundo método $n^{\circ} 942.15$ da AOAC (2005).

\section{Análise estatística dos resultados}

Os resultados obtidos das avaliações de coloração foram submetidos à análise de variância (ANOVA) pelo Teste $\mathrm{F}$ e comparação das médias pelo Teste de Tukey (5\%) utilizando-se o sistema estatístico Statistical Analysis System (SAS, 1996). Para os dados referentes às análises de $\mathrm{pH}$ e acidez titulável foram retiradas as médias dos tratamentos. As análises estatísticas consideraram os períodos de armazenamento e as soluções de envase determinadas.

\section{Resultados e Discussão}

Os valores médios para $\mathrm{pH}$ dos palmitos (Figura 2) mantiveram-se seguros com $\mathrm{pH}$ abaixo de 4,5 até o $7^{\circ}$ dia de armazenamento para o C. botulinum. No último período de análises contando 14 dias de armazenamento, o valor de $\mathrm{pH}$ dos tratamentos $\mathrm{A}$, C e D $(0,025 \%, 0,6 \%$ e $0,825 \%$ de ácido cítrico na salmoura respectivamente) apresentaram acréscimo de valor. O tratamento A mostrou neste período valor de $\mathrm{pH}$ superior a 4,5 , propiciando o crescimento de $C$. botulinum, tal fato pode ser devido à sua salmoura possuir a menor porcentagem de ácido cítrico, o que não possibilitou acidificação adequada do produto durante o período de armazenamento, em que o palmito e a salmoura entram em equilíbrio de $\mathrm{pH}$. Os palmitos dos tratamentos $\mathrm{B}$ e C estiveram no limiar do valor de $\mathrm{pH}$ aceito para segurança microbiológica, sendo assim não considerados aptos para o consumo humano.

Os valores de acidez titulável encontrados nos diversos tratamentos para os palmitos minimamente processados foram considerados adequados durante o período de armazenamento analisado (Figura 3). Esses valores são maiores que os obtidos por Kapp et al. (2003) em que a média das amostras de palmito de pupunha minimamente processados estavam entre 0,01 e $0,05 \%$. Tal diferença é devido ao fato de que os palmitos de juçara minimamente processados foram armazenados em bolsas plásticas contendo salmoura acidificada, o que conferiu maior grau de acidez nos produtos.

Os valores de coloração L (luminosidade), Croma (saturação da cor), e ângulo Hue (tonalidade) não apresentaram diferenças estatísticas a 5\% de probabilidade entre períodos e tratamentos (Tabelas 1, 2 e 3), sendo considerada como escura esverdeada. Percebeu-se que os palmitos de todos os tratamentos escureceram durante o armazenamento, tornandoos inaptos ao consumo humano. Os toletes do tratamento D (salmoura com $0,825 \%$ de ácido cítrico) apresentaram menor escurecimento, tal fato pode ser atribuído pela maior acidificação da salmoura, que provavelmente inativou parte das enzimas de escurecimento polifenoloxidase e peroxidase. 


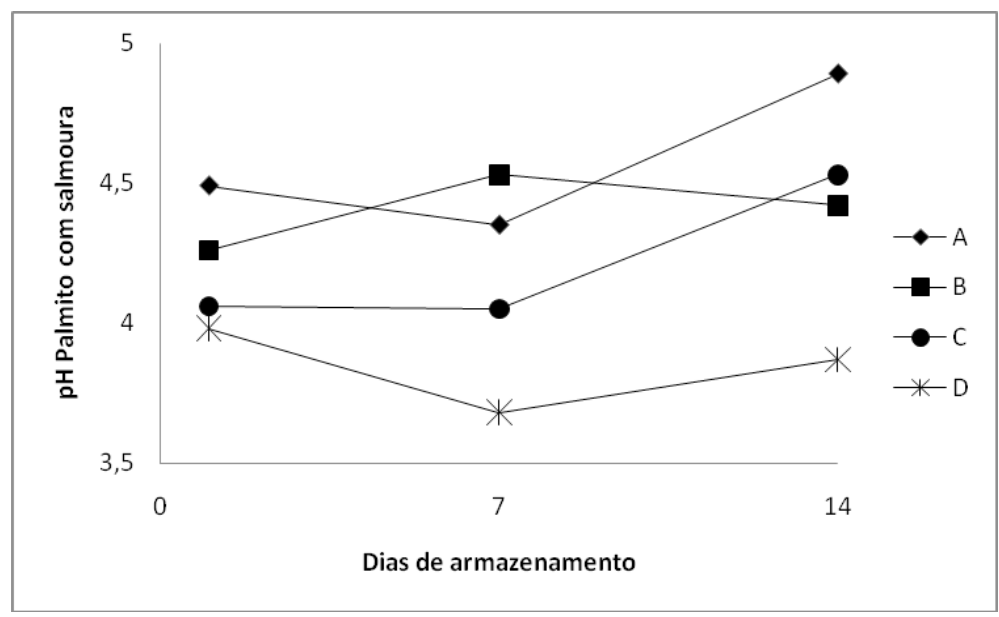

Figura 2. Valores de $\mathrm{pH}$ determinados para os toletes de palmito juçara.

Fonte: A: palmito em solução 0,025\% de ácido cítrico; B: palmito em solução 0,375\% de ácido cítrico; C: palmito em solução $0,6 \%$ de ácido cítrico; D: palmito em solução $0,825 \%$ de ácido cítrico.

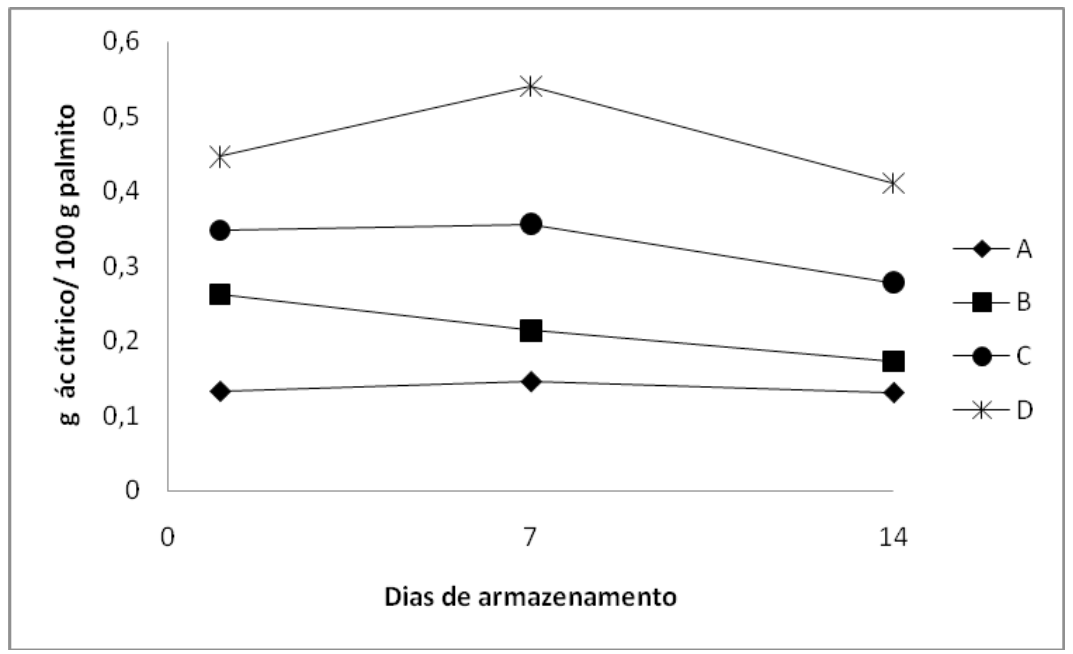

Figura 3. Valores de acidez titulável ( $\mathrm{g}$ ácido cítrico/100 g de palmito) determinados para os toletes de palmito juçara. Fonte: A: palmito em solução 0,025\% de ácido cítrico; B: palmito em solução 0,375\% de ácido cítrico; C: palmito em solução $0,6 \%$ de ácido cítrico; D: palmito em solução $0,825 \%$ de ácido cítrico.

Tabela 1. Luminosidade (L) para toletes de palmito juçara embalados em salmoura.

\begin{tabular}{ccccc}
\hline \multicolumn{5}{c}{ Períodos de armazenamento (dias) } \\
\hline Tratamentos & 1 & 7 & 14 & Médias \\
\hline A & 70,173 & 80,526 & 66,207 & 72,302 \\
B & 76,600 & 72,613 & 66,717 & 71,977 \\
C & 60,053 & 74,337 & 62,593 & 65,661 \\
D & 79,113 & 77,163 & 66,097 & 74,124 \\
\hline Médias & 71,485 & 76,160 & 65,403 & - \\
\hline
\end{tabular}

A: palmito em solução $0,025 \%$ de ácido cítrico; B: palmito em solução $0,375 \%$ de ácido cítrico; C: palmito em solução $0,6 \%$ de ácido cítrico; D: palmito em solução $0,825 \%$ de ácido cítrico. 
Tabela 2. Croma para toletes de palmito juçara embalados em salmoura acidificada.

\begin{tabular}{ccccc}
\hline \multicolumn{5}{c}{ Períodos de armazenamento (dias) } \\
\hline Tratamentos & 1 & 7 & 14 & Médias \\
\hline A & 18,737 & 16,357 & 12,963 & 16,019 \\
$\mathrm{~B}$ & 14,833 & 16,573 & 17,134 & 16,180 \\
$\mathrm{C}$ & 13,933 & 11,850 & 13,417 & 13,067 \\
$\mathrm{D}$ & 14,987 & 17,600 & 19,943 & 17,510 \\
\hline Médias & 15,623 & 15,595 & 15,864 & - \\
\hline
\end{tabular}

A: palmito em solução $0,025 \%$ de ácido cítrico; B: palmito em solução $0,375 \%$ de ácido cítrico; C: palmito em solução $0,6 \%$ de ácido cítrico; D: palmito em solução $0,825 \%$ de ácido cítrico.

Tabela 3. Ângulo Hue (graus) para toletes de palmito juçara embalados em salmoura acidificada.

\begin{tabular}{ccccc}
\hline \multicolumn{5}{c}{ Períodos de armazenamento (dias) } \\
\hline Tratamentos & 1 & 7 & 14 & Médias \\
\hline A & 145,760 & 93,293 & 149,903 & 129,650 \\
B & 94,340 & 203,650 & 196,907 & 164,97 \\
C & 94,427 & 205,140 & 248,353 & 182,64 \\
D & 151,347 & 201,557 & 251,670 & 201,52 \\
\hline Médias & $121,47 \mathrm{~B}$ & $175,91 \mathrm{AB}$ & $211,71 \mathrm{~A}$ & - \\
\hline
\end{tabular}

A: palmito em solução $0,025 \%$ de ácido cítrico; B: palmito em solução $0,375 \%$ de ácido cítrico; $C$ : palmito em solução $0,6 \%$ de ácido cítrico; D: palmito em solução $0,825 \%$ de ácido cítrico.

\section{Conclusão}

Os palmitos minimamente processados de juçara embora tenham apresentado $\mathrm{pH}$ dentro da faixa de segurança para o Clostridium botulinum e acidez titulável adequada durante o período de armazenamento, não são próprios para o consumo, devido ao escurecimento enzimático que deixou o produto visualmente descaracterizados. Concluise, portanto, que o processamento mínimo de palmito de juçara não é efetivo. Para o produto ser comercializado é necessário a realização da etapa de branqueamento, responsável pela inativação das enzimas de escurecimento, o que não caracteriza o palmito como minimamente processado.

\section{Referências}

ASSOCIATION OF OFFICIAL ANALYTICAL CHEMISTS - AOAC. Official methods of analysis. $18^{\text {th }}$. ed. Editors William Horwitz, George Latiner. Gaithersburg: AOAC International, 2005.
CAMARGO, R. Tecnologia dos produtos agropecuários - alimentos. São Paulo: Nobel, 1984.

CHAIMSOHN, F. P. Cultivo de pupunha e produção do palmito. Viçosa: Aprenda Fácil. 2000. 121 p.

Cultivo de pupunha para palmito. Importância, mercado e aspectos biológicos e agronômicos. In: CHAIMSOHN, F. P. (Coord.). Curso sobre cultivo e processamento de palmito de pupunha e introdução ao cultivo de palmeira real para palmito. Londrina: Instituto Agronômico do Paraná, IAPAR, 2001. p. 144-149.

CHEFTEL, J. C.; CHEFTEL, H.; BESANÇON, P. Introducción a la bioquímica y tecnología de los alimentos. In:_. Pardeamiento enzimatico. Zaragoza, España: Editorial Acribia, 1992. v. 1, p. 309318 .

CLEMENT, C. R.; BOVI, M. L. A. Novos mercados para palmito minimamente processado e pronto para uso. In: SEMINÁRIO DO AGRONEGÓCIO, 1., 1999. Porto Velho. Anais... Porto Velho: EMBRAPA/CPAF, Rondônia, 1999, p. 19-23. (Documentos, n. 41).

CONTE, R. Estrutura genética de populações de Eterpe edulis Mart. Submetidas à ação antrópica utilizando marcadores alozímicos e microssatélites. 2004. Tese 
(Doutorado em Agronomia) - Escola Superior de Agricultura Luiz de Queiroz. Universidade de São Paulo, Piracicaba.

FERREIRA, V. L. P.; GRANER, M.; BOVI, M. L. A.; DRAETTA, I. S.; PASCHOALINO, J. E.; SHIROSE, I. Comparação entre os palmitos de Guilielma gasipaes Bailey (pupunha) e Euterpe edulis Mart. (juçara). II. Avaliações físicas e químicas. Coletânea do Instituto de Tecnologia de Alimentos, Campinas, v. 12, n. 1, p. 273282, 1982.

FRANCO, B. D. G. M.; LANDGRAF, M. Microbiologia dos alimentos. In: Microrganismos patogênicos de importância em alimentos. São Paulo: Atheneu, 1996. p. 33-41.

GAVA, A. J. Princípios de tecnologia de alimentos. Rio de Janeiro: Nobel, 1978.

KAPP, E. A.; PINHEIRO, J. L.; RAUPP, D. S.; CHAIMSOHN, F. P. Tempo de preservação de tolete de palmito pupunha (bactris gasipaes) minimamente processado e armazenado sob refrigeração. Publicatio UEPG Ciências Exatas e da Terra, Ponta Grossa, v. 9, n. 3, p. 51-57, dez. 2003.

LINDEN, G.; LORIENT, D. Bioquímica agroindustrial. Zaragoza: Editorial Acribia, 1996.

MINOLTA, K. Comunicação precisa da cor: controle de qualidade da percepção à instrumentação. Osaka: Konika Minolta Sensing, INC., 1998. 59 p.

MORETTI, C. L. Processamento mínimo de hortaliças: tendências e desafios. Horticultura Brasileira, Campinas, v. 19, jul. 2001. Suplemento.

PASCHOALINO, J. E. Hortaliças acidificadas em conserva: riscos e cuidados. Informativo Fruthotec, Instituto de Tecnologia de Alimentos, Campinas, v. 3, n. 2, p. 1-7, 1997.

Processamento de horaliças. Manual Técnico, Instituto de Tecnologia de Alimentos, Campinas, v. 4, p. 1-70, 1994.
PASCHOALINO, J. E.; CAMPOS, S. D. S.; LEITÃO, M. F. F. Cinética do amolecimento térmico do palmito (E. edulis Mart.). Coletânea do Instituto de Tecnologia de Alimentos, Campinas, v. 19, n. 2, p. 144-153, jul./dez. 1989.

RAUPP, D. S. O envase de palmito de pupunha em vidro. In: CHAIMSOHN, F. P.; SKORA NETO, F.; SANTOS, A. F.; TESSMANN, D. J.; DURIGAN, M. E.; TREITNY, M. R.; HERNADEZ, F. B. T.; RAUPP, D. S. Curso sobre cultivo e processamento de palmito de pupunha e introdução ao cultivo de palmeira real para palmito. Londrina: IAPAR, 2001. p. 127-138.

SOARES, A. G. Palmito de pupunha - alternativas de processamento. Revista de Horticultura Brasileira, Brasília, v. 15, p. 198-199, 1997.

STATISTICAL ANALISIS SYSTEM INSTITUTE. SAS/ QC software: usage and reference (version 6). $2^{\text {th }}$ ed. Cary, 1996. 1 CD-ROM.

TONET, R. M.; FERREIRA, L. G. S.; OTOBONI, J. L. M. A. A cultura da pupunha. Boletim Técnico, Coordenadoria de Assistência Técnica Integral (Cati), Campinas, v. 237, p. 1-44, 1999.

WILEY, R. C. Frutas y hortalizas mínimamente procesadas y refrigeradas. Zaragoza, Espanha: Editorial Acribia, 1997. $362 \mathrm{p}$.

YUYAMA, K. Melhoramento de pupunheira para produção de palmito no INPA. In: REUNIÃO TÉCNICA DO PROJETO DE PROBIO/MMA PUPUNHA RAÇAS PRIMITIVAS E PARENTES SILVESTRES, 2005, Manaus, Amazonas. Relatório... Manaus, Amazonas: INPA, 2005.

ZAPATA, M. M.; QUAST, D. G. Curvas de titulação do palmito-doce (Euterpe edulis Mart.). Coletânea do Instituto de Tecnologia de Alimentos, Campinas, v. 6, p. 167-187, 1975. 